\title{
Electrochemical Characteristics of Natural Mineral Covellite
}

\author{
Mirjana Rajčić-Vujasinović ${ }^{1}$, Zoran Stević ${ }^{1}$, Sanja Bugarinović ${ }^{2}$ \\ ${ }^{1}$ Technical Faculty in Bor, University of Belgrade, Bor, Serbia \\ ${ }^{2}$ Mining and Metallurgy Institute, Zeleni Bulevar, Bor, Serbia \\ Email: mrajcic@tf.bor.ac.rs, zstevic@tt.bor.ac.rs, sanjab@ptt.rs
}

Received June 23, 2012; revised July 26, 2012; accepted August 15, 2012

\begin{abstract}
Electrochemical characteristics of covellite (CuS) are of importance from flotation and metallurgical point of view, as well as due to its potential application in solid state solar cells and in photocatalytic reactions. Also, the compound $\mathrm{CuS}$ appears as an intermediary product or a final product in electrochemical oxidation reactions of chalcocite $\left(\mathrm{Cu}_{2} \mathrm{~S}\right)$ which exhibits supercapacitor characteristics. Natural copper mineral covellite has been investigated in inorganic sulfate acid electrolytes, as well as in strong alkaline electrolyte. Physical properties of covellite were characterized by X-ray diffraction (XRD) and the active surface was examined by optical and electron microscopy (EM) before and after oxidation in galvanostatic regime. Different electrochemical methods (galvanostatic, potentiostatic, cyclic voltammetry and electrochemical impedance spectroscopy-EIS) have been used. The capacitance of around $21 \mathrm{Fcm}^{-2}$ (geometric area), serial resistance of about $90 \Omega \mathrm{cm}^{2}$ and leakage resistance of about $1200 \Omega \mathrm{cm}^{2}$ have been measured in $1 \mathrm{M} \mathrm{H}_{2} \mathrm{SO}_{4}$. The addition of cupric ions in sulfate electrolyte leads to the significant increasing of the capacitance, but having the increase of self-discharge as a negative side phenomenon. The capacitance of around $6.7 \mathrm{Fcm}^{-2}$ (geometric area), serial resistance of about $80 \Omega \mathrm{cm}^{2}$ and leakage resistance of about $380 \Omega \mathrm{cm}^{2}$ have been measured in $6 \mathrm{M} \mathrm{KOH}$.
\end{abstract}

Keywords: Covellite; Capacitance; Copper Sulfides; Electrochemical Characterization; Solar Cells

\section{Introduction}

Copper sulphides were largely investigated in the recent years due to the interesting optical and electrical properties, resulted from the variations in stoichiometry, composition, morphology, and due to their potential applications in various fields such as absorbers for solid state solar cells or in photocatalytic reactions [1]. Solid-state solar cells are considered attractive devices for the next generation of photovoltaic cells. Copper sulfides can be considered in some ways ideal absorber materials - being non-toxic, cheap and, importantly, abundant, and with good absorption characteristics. An ETA (Extremely Thin Absorber) cell is one of the few configurations with potential to exploit the favourable qualities of $\mathrm{CuS}$ in a low-cost solar cell. Additionally, $\mathrm{CuS}$ can be considered a model electronically "poor" semiconductor, and construction of a good solar cell with it would be clear proof of the ETA principle [2].

It was found that different natural sulfide minerals such as pyrite $\left(\mathrm{FeS}_{2}\right)$ [3] and chalcocite $\left(\mathrm{Cu}_{2} \mathrm{~S}\right)$ [4], as well as metal sulfides obtained by chemical precipitation, like cobalt sulfide [5] or nano $\mathrm{SnS}$ [6] and $\mathrm{ZnS}$ [7], exhibit capacitance characteristics in aqueous solutions of some acids and alkaline. Compound CuS appears as an intermediary product or a final product in electrochemical oxidation reactions of chalcocite which exhibits supercapacitor characteristics. The common characteristic of sulfides exhibiting high capacitances is that their metal constituent can appear in two or more valence states. Also, while modeling anodic oxidation reaction of covellite, it was established that the equivalent electrical circuit has to contain one relatively high capacitor [8]. Those facts were the reason for examination of the mineral covellite capacitive characteristics.

Covellite is a copper mineral that can be found in some copper mines as the relatively pure massive samples. Its chemical composition is between $\mathrm{CuS}$ and $\mathrm{Cu}_{1.1} \mathrm{~S}$. Natural covellite has a hexagonal crystal lattice with the parameters $\mathrm{a}_{0}=0.3972 \pm 0.0001 \mathrm{~nm}$ and $\mathrm{c}_{0}=$ $1.6344 \pm 0.01 \mathrm{~nm}$, but sometimes it can appear as monoclinic [9]. Natural covellite is a semiconductor, but its electrical resistivity is in order of magnitude $10^{-6} \Omega \mathrm{m}$, that is near to metals $[10,11]$. It was proved by thermoelectric probe that covellite is a p-type semiconductor [12] and confirmed by photoelectrical testing of the samples from Bor copper mine [13]. Most results of electrochemical investigations of copper minerals can be found 
in older literature, but mainly from the metallurgical point of view [14-26]. Yin et al. [27,28] investigated behavior of covellite and other copper sulfides with emphasize on their oxidation in alkaline solutions.

\section{Experimental}

The applied standard electrochemical methods such as galvanostatic, cyclic voltammetry, potentiostatic method and impedance spectroscopy (EIS), and other methods of material characterization (optical and scanning electron microscopy) were described elsewhere [3,8,13,25,29-33].

\subsection{Equipment}

The electrochemical characterization was carried out by a standard three-electrode system consisting of saturated calomel electrode (SCE) as a reference electrode, platinum as a counter electrode and a number of working electrodes the active part of which is the tested material. The contact between the copper wire and the electrode material was achieved by using conducting silver glue, and then mounted in acrylic mass for cold mounting. The working electrodes (five of them) were of $18-49 \mathrm{~mm}^{2}$ and counter electrode of $200 \mathrm{~mm}^{2}$ of active surface area.

The system for electrochemical measurements consisted of hardware (PC, AD-DA converter NI 6251 from National Instruments and analog interface developed on Technical faculty in Bor) and software for excitation and measurement (LabVIEW platform and application software) [33].

The optic microscopy of electrode material was carried out by using LOMO MIN9 microscope with digital camera JENOPTIK ProgRes C10+ for the immediate records transfer into the computer. The electronic microscopy was performed by using JSM 35 microscope. The X-ray analysis was done by Siemens difractometer Kristaloflex 810 .

\subsection{Materials}

The starting material was samples of natural copper mineral covellite from Bor copper mine. The first series of experiments was done in unimolar aqueous solutions of sulfuric acid with or without the addition of copper sulfate. The experiments in the second series were performed in strong alkaline solution $(6 \mathrm{M} \mathrm{KOH})$. Analytical grade reagents (sulfuric acid, copper sulfate and potassium hydroxide made by "Zorka" Šabac, Serbia) were used without further purification. Solutions were prepared with distilled water and were not de-aerated.

The polished surface of the material was analyzed by optic and electronic microscopy, before and after the application of galvanostatic impulse of $0.5 \mathrm{~mA}$ for the duration of $40 \mathrm{~s}$ in $1 \mathrm{M} \mathrm{H}_{2} \mathrm{SO}_{4}$ electrolyte. Figures 1(a) and 1(b) show optic microscopy pictures of non-treated (a) and treated (b) covellite. Uniform surface of the non-treated sample confirms its high purity concerning natural mineral; natural minerals usually contain some impurities like quartz or pyrite. It is obvious from Figure 1(b) that some product appeared on the treated electrode surface during the anodic process. The structure of this product may be considered as the main reason of relatively high capacitance found out at covellite and other copper minerals, especially chalcocite.

The chemical composition of the material was determined by X-ray diffraction analysis of numerous samples, one of which is presented by the diagram in Figure 2 . The pattern shows that the main constituent of the sample is compound $\mathrm{CuS}$.

\subsection{Procedures}

For each set of experiments working electrodes were ground, polished, washed out, dried and, finally, submerged into electrolyte fresh made for each series of experiments. Polishing and washing out (without grinding) was done between two experiments. Grinding was performed by the finest grinding paper, polishing by alumina $(0.05 \mu \mathrm{m})$ and washing out by distilled water and alcohol.

All the experiments were performed at room temperature. Having submerged the working electrode, its potential versus the reference electrode was observed, and, after stabilization, the value of the rest potential was

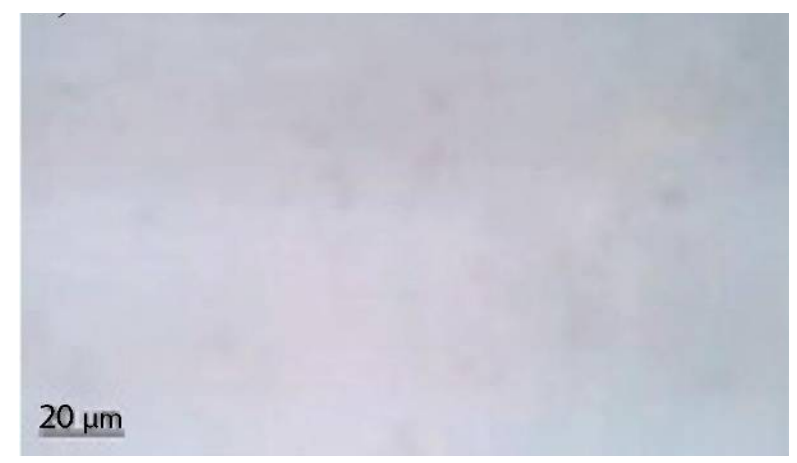

(a)

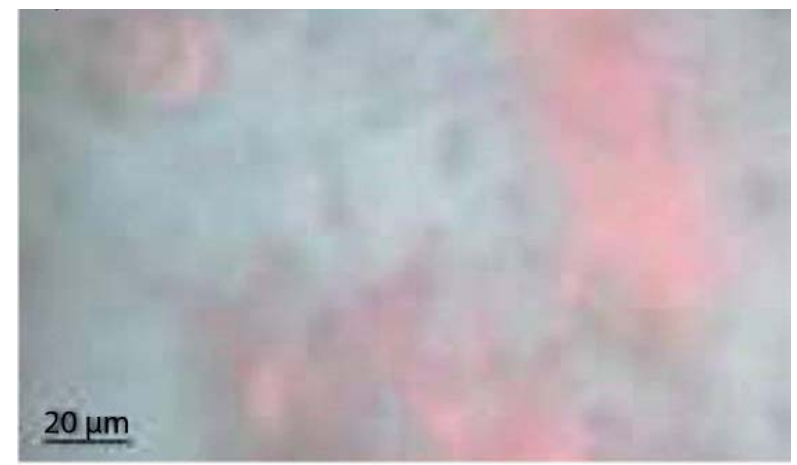

(b)

Figure 1. Microscopic picture of non-treated (a) and treated (b) covellite. 


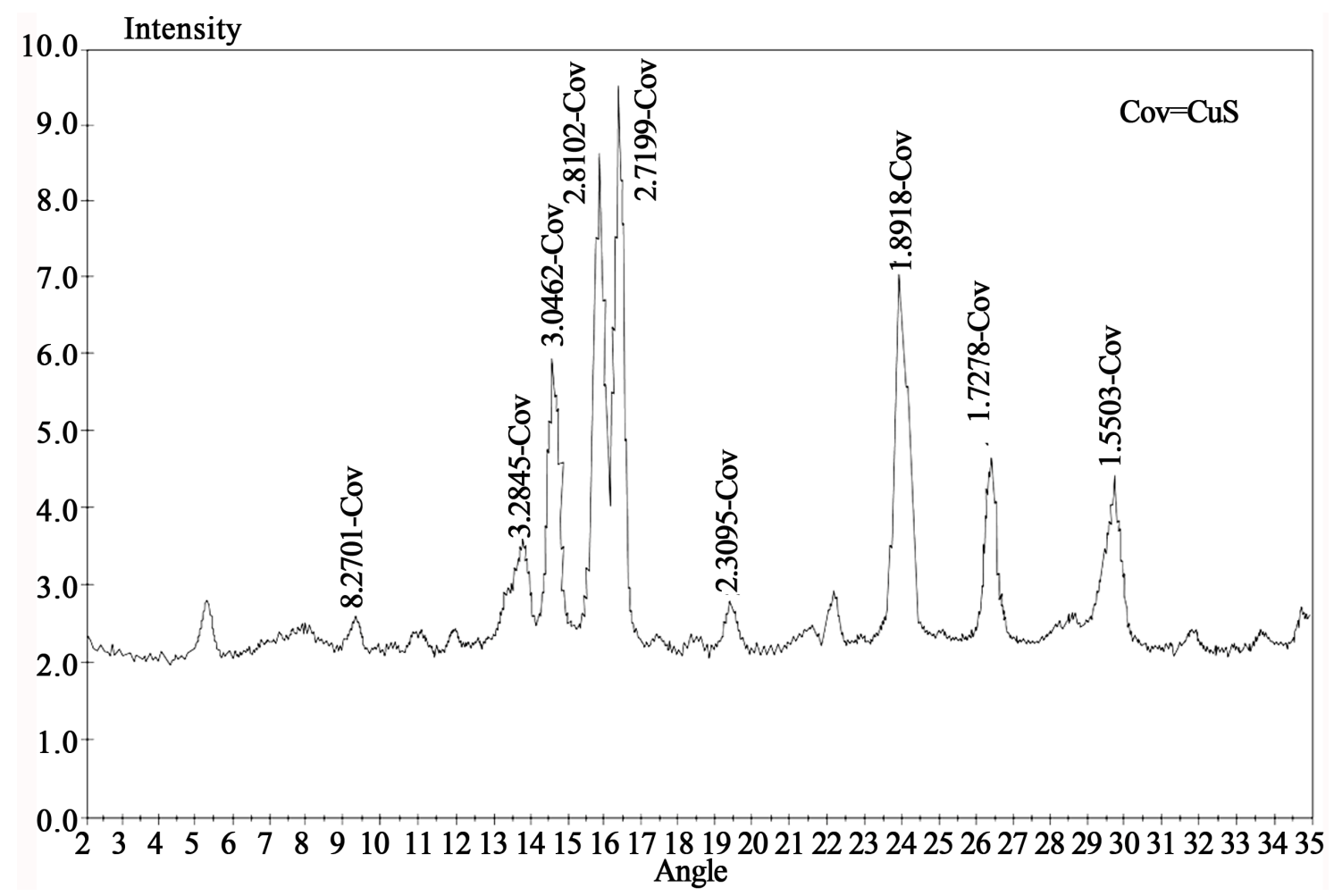

Figure 2. X-ray diffraction pattern of natural mineral covellite.

noted down. The value was used to determine parameters of subsequent experiments depending on the method of examination.

\section{Theoretical Part}

\subsection{Possible Reaction Mechanisms}

Oxidation of a sulfide mineral is a multi step process made up of a series of consecutive reactions. In literature [12-25] it can be found a series of assumptions about the mechanism of electrochemical oxidation of copper sulfides chalcocite and covellite. Most authors confirm that the overall reaction of anodic dissolution of covellite in acid solutions is:

$$
\mathrm{CuS}=\mathrm{Cu}^{2+}+\mathrm{S}^{0}+2 e^{-}
$$

Electronic microscopy confirms the presence of elemental sulfur on the surface of anodically treated covellite, but there is very low probability of the two electron transfer in one step because the activation energy of such reactions is very high in compare to one electron transfers. Also, that reaction is almost completely irreversible.

More probable mechanism consisting of two one-electron steps is:

$$
\mathrm{CuS}=\mathrm{Cu}^{+}+\mathrm{S}^{0}+e^{-}
$$

followed by:

$$
\mathrm{Cu}^{+}=\mathrm{Cu}^{2+}+2 e^{-}
$$

Some authors [14] presume that the first step is the discharge of hydroxide ions and oxygen evolution at CuS:

$$
2 \mathrm{OH}^{-}=\mathrm{H}_{2} \mathrm{O}+\mathrm{O}+2 e^{-}
$$

Further dissolution in acid and week alkaline solutions proceeds by chemical oxidation of $\mathrm{CuS}$ with atomic oxygen produced in previous step:

$$
\mathrm{CuS}+\mathrm{O}+\mathrm{H}_{2} \mathrm{SO}_{4}=\mathrm{CuSO}_{4}+\mathrm{S}^{0}+\mathrm{H}_{2} \mathrm{O}_{\text {(liq) }}
$$

Elemental sulfur also can be oxidized with atomic oxygen, which is very reactive:

$$
\mathrm{S}+2 \mathrm{O}=\mathrm{SO}_{2}
$$

or

$$
\mathrm{S}+3 \mathrm{O}+\mathrm{H}_{2} \mathrm{O}=\mathrm{H}_{2} \mathrm{SO}_{4}
$$

Previous investigations performed mainly in acid solutions $[8,13,23,25]$ lead to the assumption that the metal ions from the mineral crystal lattice are transferred into the solution leaving a surface region with the higher content of sulfur. That sulfur can be treated as adsorbed species giving rise to the pseudocapacitance exhibited by $\mathrm{CuS}$ and $\mathrm{Cu}_{2} \mathrm{~S}$.

In strong alkaline solutions covellite is thermodynamiccally instable compound, as well as elementary sulfur. Because of that, in a medium of this kind, the reaction (4) may be followed by: 


$$
2 \mathrm{CuS}+4 \mathrm{H}_{2} \mathrm{O}=\mathrm{Cu}_{2} \mathrm{~S}+\mathrm{SO}_{4}{ }^{2-}+8 \mathrm{H}^{+}+6 e^{-}
$$

All product species in the reaction (8) are thermodynamically stable in strong alkaline solutions [10].

\subsection{Equivalent Electrical Circuit}

In a goal to achieve mathematical analysis of the measured data, it was necessary to develop mathematical model adapted to the investigated class of electrochemical system and it is strongly connected with the physical parameters of the system. Adopted equivalent circuit in a general case is given in Figure 3(a). $\mathrm{R}_{0}$ corresponds to the resistance of electrolyte and electrode material, and its value is in order of magnitude milliohm $(\mathrm{m} \Omega)$ or ohm $(\Omega)$. Capacity $\mathrm{C}_{0}$ corresponds to double layer formed on the electrolyte side. Resistances $R_{1}$ and $R_{2}$ (order of magnitude ohm to dozen ohms) are related to slow processes of adsorption and diffusion, as well as the capacitances $\mathrm{C}_{1}$ and $\mathrm{C}_{2}$. As a matter of fact, the branch $\mathrm{R}_{1} \mathrm{C}_{1}$ exhibits and describes the inconstancy of parameters in $\mathrm{R}_{2} \mathrm{C}_{2}$ branch. $\mathrm{R}_{3}$ is resistance of self-discharging, meaning that it is reciprocal to leakage current. Its value is in order of hundred ohms till the dozens of kilo ohms.

The equation for impedance for equivalent circuit given in Figure 3(a) is complex and not enough clear. So, knowing the nature of the process, i.e. orders of magnitude of the circuit parameters, much simpler circuit is applied for analysis and characterization of systems like investigated here. The scheme of that system is presented in Figure 3(b), $R_{s}$ being total serial resistance of the system, $\mathrm{C}$-integral capacitance, $\mathrm{R}_{\mathrm{L}}$ - parallel resistance of self discharge (leakage).

\section{Results and Discussion}

The next electrochemical methods have been used: galvanostatic, cyclic voltammetry, potentiostatic method and impedance spectroscopy (EIS). In a goal to determine the main parameters, investigated electrochemical system was modeled by a simplified equivalent circuit which consisted of a main capacitance, a serial resistance and leakage resistance $[25,34]$.

\subsection{Galvanostatic Examination}

Classic galvanostatic method assumes that the system is excited by the constant current between working and as the system response. Besides the classical, the modified method $[32,34]$ with prolonged duration of current impulse is applied in order to allow the overwhelming system analysis. The surface of the electrode is also analyzed before and after the use of galvanostatic impulse.

Figure 4 shows an electronic microscopy picture of the covellite sample before and after the application of

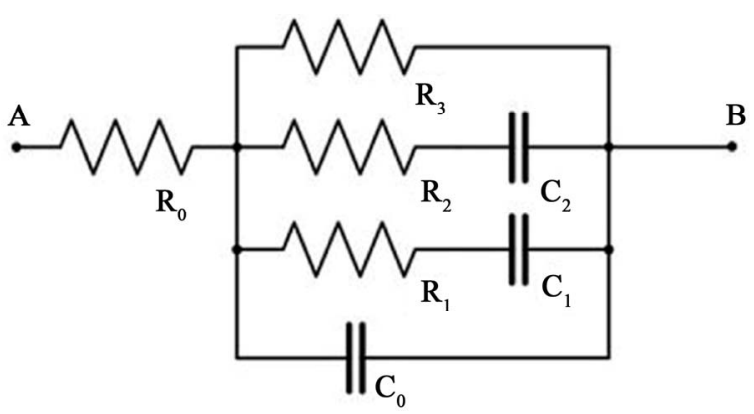

(a)

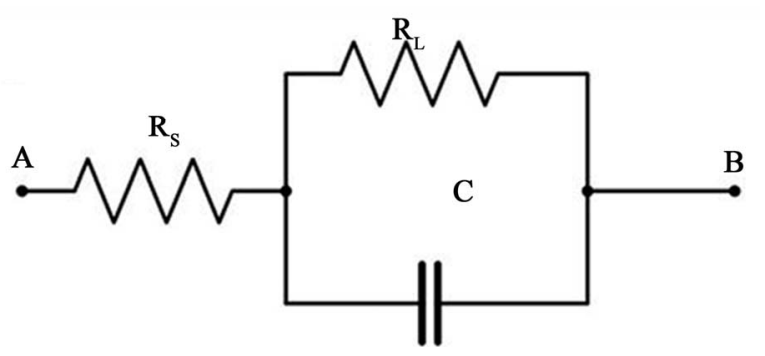

(b)

Figure 3. Equivalent electrical circuit; (a) complete, (b) simplified.

galvanostatic impulse of $0.5 \mathrm{~mA}$ for the duration of $40 \mathrm{~s}$ in $1 \mathrm{M} \mathrm{H}_{2} \mathrm{SO}_{4}$ electrolyte. The consequences of the reaction on the treated samples are obvious so as their non- homogeneous surface layer, noticeably porous, hence the increase of the electrode interface.

A series of experiments in the $0.5 \mathrm{M} \mathrm{H}_{2} \mathrm{SO}_{4}+1 \mathrm{M}$ $\mathrm{NaCl}$ electrolyte showed the intense self-discharge effect (electrodes tend to relax quickly), so the project was abandoned.

All the prepared electrodes were first examined in the unimolar solution of pure sulfuric acid $\left(1 \mathrm{M} \mathrm{H}_{2} \mathrm{SO}_{4}\right)$. Galvanostatic curve for the covellite electrode (surface area $0.38 \mathrm{~cm}^{2}$ ) subjected to excitation of $0.1 \mathrm{~mA}$ for the duration of $80 \mathrm{~s}$ in the solution of unimolar sulfuric acid is given in Figure 5. Serial resistance of about $90 \Omega \mathrm{cm}^{2}$ has been determined from the diagram.

Galvanostatic investigations with the same electrodes have been performed in a strong alkaline solution, as well. Galvanostatic curve for the covellite electrode (surface area $0.42 \mathrm{~cm}^{2}$ ) subjected to excitation of $1 \mathrm{~mA}$ for the duration of $80 \mathrm{~s}$ in the solution of $6 \mathrm{M} \mathrm{KOH}$ is given in Figure 6. Serial resistance of about $80 \Omega \mathrm{cm}^{2}$ has been determined from the diagram.

\subsection{Cyclic Voltammetry}

Since the standard cyclic voltammetry method is very convenient for capacitance measurements, a series of experiments was carried out in various electrolytes.

Figure 7 presents a series of voltammograms obtained in $1 \mathrm{M} \mathrm{H}_{2} \mathrm{SO}_{4}$ by cycling with the sweep rate of $5 \mathrm{mVs}^{-1}$. 


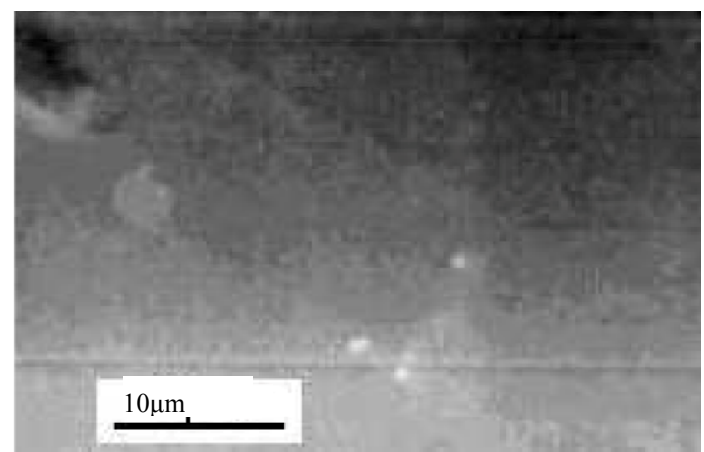

(a)

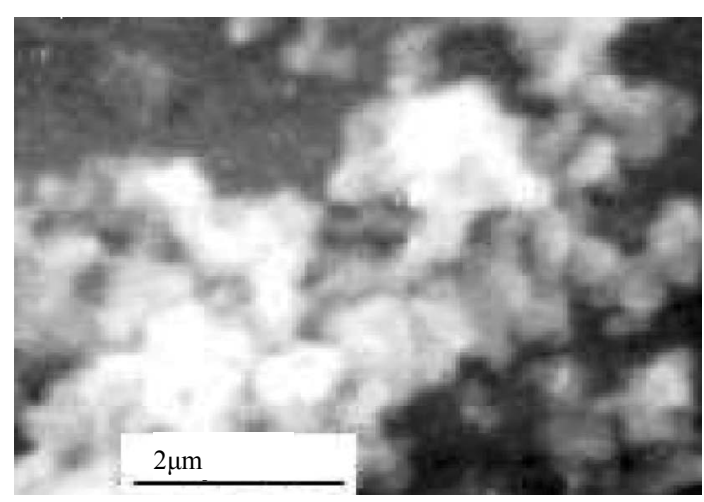

(b)

Figure 4. Electronic microscopy picture of non-treated (a) and treated (b) covellite.

It can be seen that the voltammetric current shows a steady decrease with the increasing of cycle numbers. The existance of a compact solid reaction product remaining on the electrode surface may be considered as the main reason of that decrease. That product causes a slow diffusion in solid state, which leads to the increase of serial resistance and controls further reaction. Capacitance calculated from the first loop surface area is around $20.6 \mathrm{Fcm}^{-2}$ (electrode active surface area $0.42 \mathrm{~cm}^{2}$ ).

Figure 8 shows voltammetric curves of covellite electrode in $6 \mathrm{M} \mathrm{KOH}$ solution obtained using a sweep rate of $5 \mathrm{mVs}^{-1}$. Capacitance calculated from the third loop is around $6.7 \mathrm{Fcm}^{-2}$ (electrode active surface area $0.42 \mathrm{~cm}^{2}$ ).

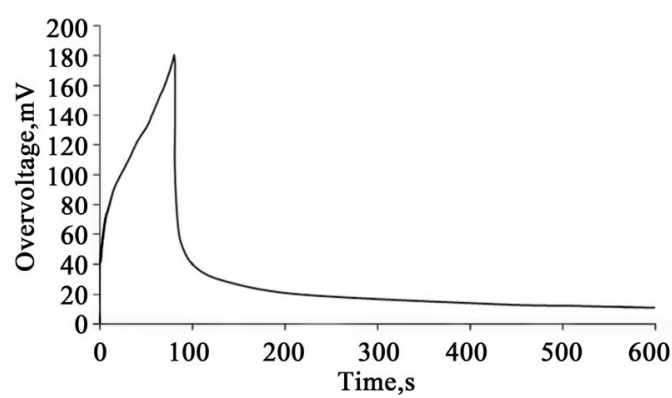

Figure 5. Galvanostatic curve of covellite in $1 \mathrm{M} \mathrm{H}_{2} \mathrm{SO}_{4}$ aqueous solution; excitation $0.1 \mathrm{~mA}, 80 \mathrm{~s}$; active surface area $0.38 \mathrm{~cm}^{2}$.

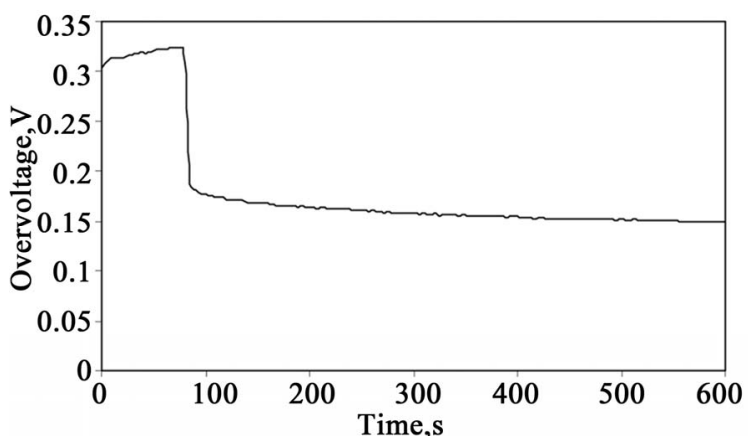

Figure 6. Galvanostatic curve of covellite in $6 \mathrm{M} \mathrm{KOH}$ aqueous solution; excitation $1 \mathrm{~mA}, 80 \mathrm{~s}$; active surface area $0.42 \mathrm{~cm}^{2}$.

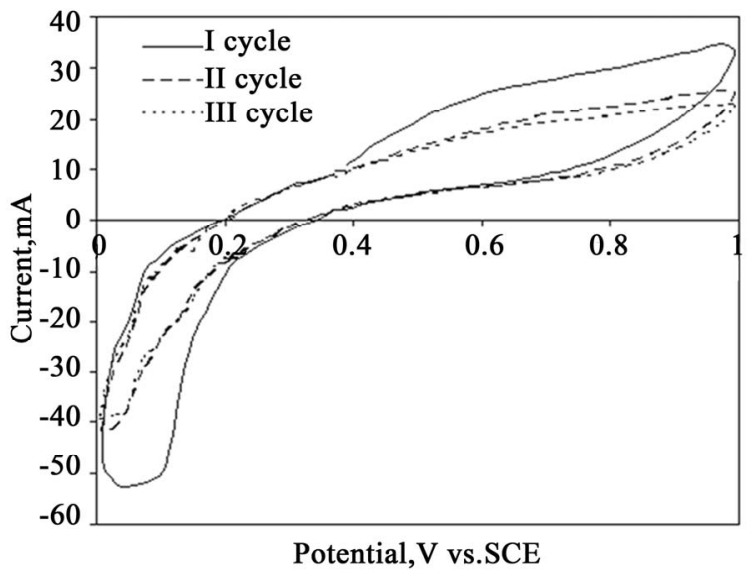

Figure 7. Cyclic voltammograms of covellite in $1 \mathrm{M} \mathrm{H}_{2} \mathrm{SO}_{4}$ at $\mathrm{v}=5 \mathrm{mVs}^{-1}$.

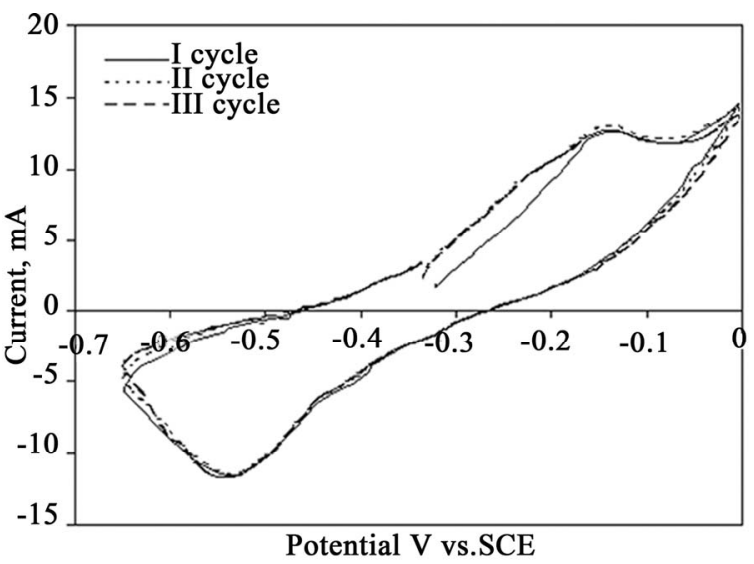

Figure 8. Consecutive cyclic voltammograms of covellite in $6 \mathrm{M} \mathrm{KOH}$ at $\mathrm{v}=5 \mathrm{mV} \mathrm{s}^{-1}$.

\subsection{Potentiostatic Research}

The advantage of potentiostatic method-relatively short duration of the experiment-was made use of for the detailed investigation of the electrode material behavior in various electrolytes for the purpose of optimum electrolyte distinction concerning the obtention of maximum capaci- 
tance and minimum leakage current.

Potentiostatic curves of covellite electrode in the solution of $1 \mathrm{M} \mathrm{H}_{2} \mathrm{SO}_{4}$ for excitation period of $100 \mathrm{~s}$ by the voltage of 20 and $100 \mathrm{mV}$ are presented in Figure 9. It was proved that the self-discharge resistance practically does not depend on overvoltage $(5000 \Omega$ at $\eta=100 \mathrm{mV}$ and $5400 \Omega$ at $\eta=20 \mathrm{mV}$ ), while leakage current is $4 \mu \mathrm{A}$ at $20 \mathrm{mV}$ and $18.5 \mu \mathrm{A}$ at $100 \mathrm{mV}$.

Potentiostatic curves obtained in electrolyte containing $1 \mathrm{M} \mathrm{H}_{2} \mathrm{SO}_{4}+0.1 \mathrm{M} \mathrm{CuSO}_{4}$ at the electrodes made of the same covellite sample, but with different suface area are presented in Figure 10. The curves confirm the supposition that the serial resistances are inversely dependent to the electrode surface area.

\subsection{Electrochemical Impedance Spectroscopy (EIS)}

Since EIS, if applied on the systems containing high capacitances, demands long duration of experiments [33] just few characteristic electrochemical systems were examined by this method.

Figure 11 shows the impedance diagram of covellite electrode in the solution of $1 \mathrm{M} \mathrm{H}_{2} \mathrm{SO}_{4}$. The excitation voltages were $\mathrm{V}_{\mathrm{DC}}=20 \mathrm{mV}, \mathrm{V}_{\mathrm{ACmax}}=5 \mathrm{mV}$. From the diagram it was obtained a capacitance of $22 \mathrm{Fcm}^{-2}$, serial resistance of $93 \Omega \mathrm{cm}^{2}$ and leakage resistance of 1160 $\Omega \mathrm{cm}^{2}$.

Figure 12 shows the impedance diagram of covellite electrode in the solution of $6 \mathrm{M} \mathrm{KOH}$. The alternate excitation voltage was $\mathrm{V}_{\mathrm{ACmax}}=7 \mathrm{mV}$, without the DC offset $\left(\mathrm{V}_{\mathrm{DC}}=0 \mathrm{mV}\right)$. From the EIS diagram it was obtained a capacitance of $9.3 \mathrm{Fcm}^{-2}$, which is in agreement with the value obtained from the cyclic voltammetry measurement. Also, from the same diagram it was obtained a serial resistance of $82 \Omega \mathrm{cm}^{2}$ and leakage resistance of $380 \Omega \mathrm{cm}^{2}$.

The addition of copper ions in the electrolyte results in the significant increasing of capacitance of investigated mineral. The same effect was noticed at the natural

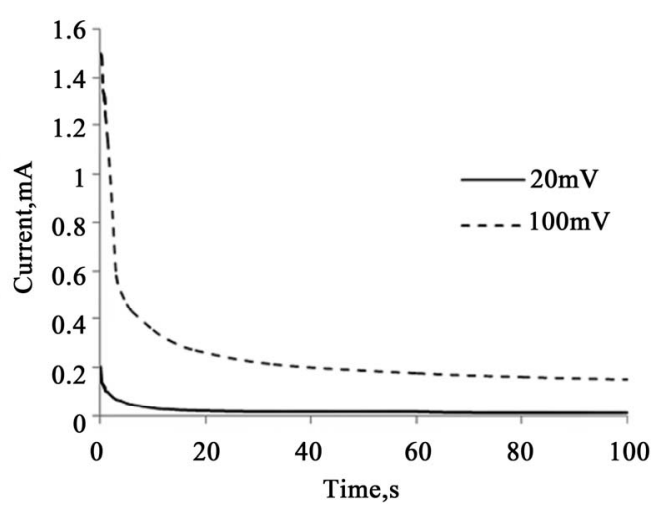

Figure 9 . Potentiostatic curves of covellite electrode in the solution of $1 \mathrm{M} \mathrm{H}_{2} \mathrm{SO}_{4}$.

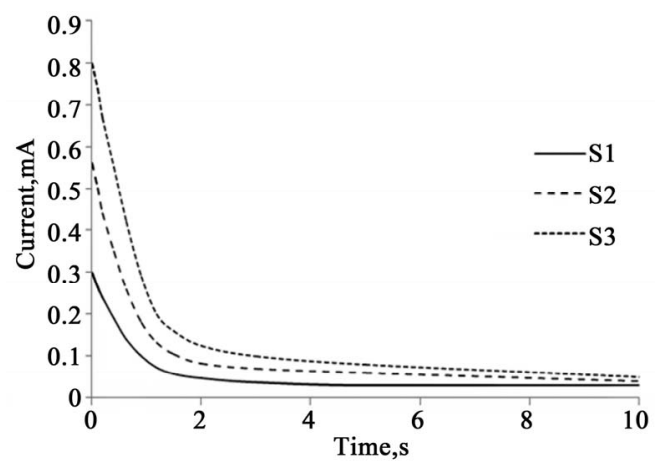

Figure 10. Family of potentiostatic curves for various electrode surface area $\left(\mathrm{S} 1=33 \mathrm{~mm}^{2} ; \mathrm{S} 2=43 \mathrm{~mm}^{2} ; \mathrm{S3}=49\right.$ $\mathbf{m m}^{2}$ ).

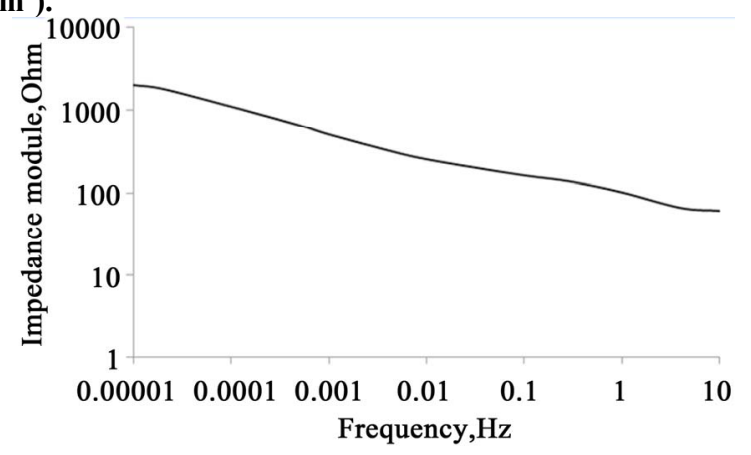

Figure 11. Impedance diagram for covellite electrode in $1 \mathrm{M}$ $\mathrm{H}_{2} \mathrm{SO}_{4}$.

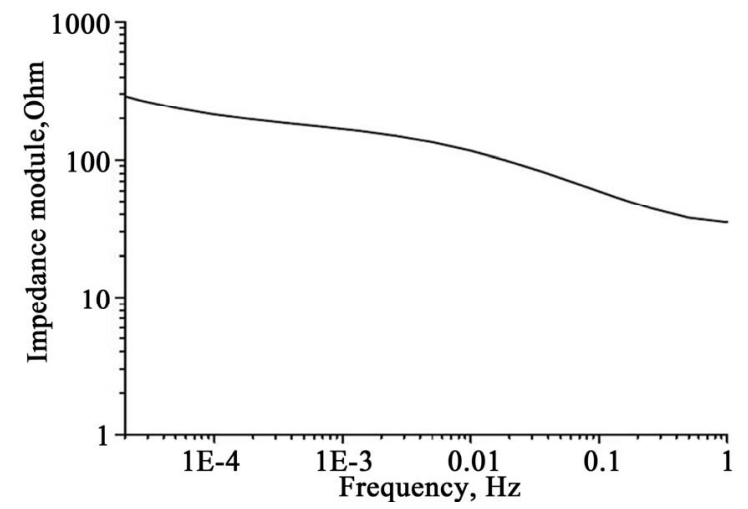

Figure 12. Impedance diagram for covellite electrode in $6 \mathrm{M}$ КОH.

copper sulfide mineral chalcocite-it was determined that its capacitance increases with the concentration of $\mathrm{CuSO}_{4}$, but having the increase of self-discharge as a side phenomenon, so the optimum concentration was estimated to be $0.1 \mathrm{M} \mathrm{CuSO}_{4}$ [4].

\section{Conclusions}

The investigations using different electrochemical methods showed that natural copper mineral covellite exibits relatively high capacitivity in order of magnitude of 20 $\mathrm{Fcm}^{-2}$ during the first anodic polarisation in acidic so- 
lutions. In the next polarisation phases, the product formed at the electrode surface causes a slow diffusion in solid state that leads to the increase of serial resistance and controls further reaction. The existance of a compact solid reaction product remaining on the electrode surface was proved by electron microscopy.

In alkaline solution covellite exhibits a capacitance of the same order of magnitude, although for about three times lower; at the same time leakage, i.e. self-discharge is bigger. The investigations on covellite in acidic and alkaline solutions had a goal to enable optimization of the electrochemical systems in the sense to obtain performances as high as possible (usually the lowest serial and biggest parallel resistance at the same time).

\section{Acknowledgment}

The authors gratefully acknowledge financial support from the Ministry of Education and Science, Government of the Republic of Serbia through the Project No. 172 060: "New approach to designing materials for energy conversion and storage".

\section{REFERENCES}

[1] M. Page, O. Niitsoo, Y. Itzhaik, D. Cahen and G. Hodes, "Copper Sulfide as a Light Absorber in Wet-Chemical Synthesized Extremely Thin Absorber (ETA) Solar Cells," Energy and Environmental Science, Vol. 2, No. 2, 2009, pp. 220-223. doi:10.1039/b813740d

[2] L. Isac, A. Duta, A. Kriza, S. Manolache and M. Nanu, "Copper Sulfides Obtained by Spray Pyrolysis-Possible Absorbers in Solid-State Solar Cells," Thin Solid Films, Vol. 515, No. 15, 2007, pp. 5755-5758. doi:10.1016/j.tsf.2006.12.073

[3] B. E. Conway, "Electrochemical Supercapacitors," Kluwer Academic/Plenum Publishers, New York, 1999.

[4] Z. Stević and M. Rajčić-Vujasinović, "Chalcocite as a Potential Material for Supercapacitors," Jourmal of Power Sources, Vol. 160, No. 2, 2006, pp. 1511-1517. doi:10.1016/j.jpowsour.2006.03.014

[5] F. Tao, Y-Q. Zhao, G-Q. Zhang and H-L. Li, "Electrochemical Characterization on Cobalt Sulfide for Electrochemical Supercapacitors," Electrochemistry Communications, Vol. 9, No. 6, 2007, pp. 1282-1287. doi:10.1016/j.elecom.2006.11.022

[6] M. Jayalakshmi, M. Mohan Rao and B. M. Choudary, "Identifying Nano SnS as a New Electrode Material for Electrochemical Capacitors in Aqueous Solutions," Electrochemistry Communications, Vol. 6, No. 11, 2004, pp. 1119-1122. doi:10.1016/j.elecom.2004.09.004

[7] M. Jayalakshmi and M. Mohan Rao, "Synthesis of Zinc Sulphides Nanoparticles by Thiourea Hydrolysis and Their Characterization for Electrochemical Capacitor Applications," Journal of Power Sources, Vol. 157, No. 1, 2006, pp. 624-629. doi:10.1016/j.jpowsour.2005.08.001
[8] M. Rajčić-Vujasinović, Z. Stanković and Z. Stević, “Consideration of the Analogue Electrical Circuit of the Metal or Semiconductor/Electrolyte Interfaces Based on the Time Transient Analysis," Russian Journal of Electrochemistry,Vol. 35, No. 3, 1999, pp. 320-327.

[9] A. A. Godvikov, "Mineralogiya," Nedra, Moscow, 1975.

[10] "Handbook of Chemistry and Physics," CRC Press, Florida, 1977.

[11] P. L. Rossiter, "The Electrical Resistivity of Metals and Alloys," Cambridge University Press, Cambridge, 1987. doi:10.1017/CBO9780511600289

[12] G. Springer, "Observations on the Electrochemical Reactivity of Semiconducting Minerals," Transactions of The Institution of Mining and Metallurgy, Vol. 79C, 1970, pp. C11-C15.

[13] M. Rajčić-Vujasinović, "Kinetics and Mechanism of Electrochemical Oxidation of Natural Mineral Covellite," Ph.D. Thesis, Technical Faculty in Bor, Bor, 1989.

[14] A. G. Loshkarev and A. F. Vozisov, "Anodic Dissolution of Copper Sulphide," Russian Journal of Applied Chemistry, Vol. 26, No. 1, 1953, pp. 55-62.

[15] M. Sato, "Half-Cell Potentials of Semiconductive Simple Binary Sulfides in Aqueous Solution," Electrochimica Acta, Vol. 11, No. 3, 1966, pp. 361-373. doi:10.1016/0013-4686(66)87046-9

[16] P. R. Kruesi, E. S. Allen and J. L. Lake, "Cymet Process Hydrometallurgical Conversion of Base-Metal Sulphides to Pure Metals," Canadian Institute of Mining, Metallurgy and Petroleum Bulletin, Vol 66, No. 734, 1973, pp. 8187.

[17] D. F. A. Koch, "Electrochemistry of Sulfide Minerals," In: J. O'M. Bockris and B. E. Conway, Eds., Modern Aspects of Electrochemistry, Plenum Press, New York, 1975, p. 211.

[18] D. J. MacKinnon, "Fluidised-Bed Anodic Dissolution of Chalcocite," Hydrometallurgy, Vol. 1, No. 3, 1976, pp. 241-257. doi:10.1016/0304-386X(76)90002-5

[19] D. J. MacKinnon, "Fluidised-Bed Anodic Dissolution of Covellite," Hydrometallurgy, Vol. 2, No. 1, 1976, pp. 6576. doi:10.1016/0304-386X(76)90014-1

[20] T. Biegler and D. C. Constable, "Continuous Electrolytic Reduction of Chalcopyrite Slurry," Journal of Applied Electrochemistry, Vo. 7, No. 2, 1977, pp. 175-179. doi:10.1007/BF00611040

[21] R. S. McMillan, D. J. MacKinnon and J. E. Dutrizac, "Anodic Dissolution of N-Type and P-Type Chalcopyrite," Journal of Applied Electrochemistry, Vol. 12, No. 6, 1982, pp. 743-757. doi:10.1007/BF00617495

[22] H. Kametani and A. Aoki, "Effect of Suspension Potential on the Oxidation Rate of Copper Concentrate in a Sulfuric Acid Solution," Metallurgical and Materials Transactions B, Vol. 16, No. 4, 1985, pp. 695-705.

[23] M. Rajčić-Vujasinović and Z. Stanković, "The Influence of Cupric Ions on the Rest Potential of Natural Covellite," Journal of Serbian Chemical Society, Vol. 52, No. 10, 1987, pp. 595-600.

[24] M. Rajčić-Vujasinović and Z. Stanković, "Chronopo- 
tentiometric Investigations of Anodic Dissolution of Natural Mineral Covellite (CuS)," Erzmetall, Vol. 47, No. 2, 1994, pp. 131-135.

[25] M. Rajčić-Vujasinović, Z. Stević and S. Djordjević, "Application of Pulse Potential for Oxidation of Natural Mineral Covellite," Russian Journal of Applied Chemistry, Vol. 67, No. 4, 1994, pp. 594-597.

[26] M. Vuković, Z. D. Stanković, M. Rajčić-Vujasinović and V. Cvetkovski, "Voltammetric Investigations of Anodic Dissolution of Natural Mineral Chalcopyrite," Journal of Mining and Metallurgy B: Metallurgy, Vol. 44, No. 1, 2008, pp. 115-124.

[27] Q. Yin, D. J. Vaughan, K. E. R. England and G. H. Kelsall, "Electrochemical Oxidation of Covellite $(\mathrm{CuS})$ in Alkaline Solution," Journal of Colloid and Interface Science, Vol. 166, No. 1, 1994, pp. 133-142. doi:10.1006/jcis.1994.1280

[28] Q. Yin, G. H. Kelsall, D. J. Vaughan and K. E. R. England, "Atmospheric and Electrochemical Oxidation of the Surface of Chalcopyrite $\left(\mathrm{CuFeS}_{2}\right)$," Geochimica et Cosmochimica Acta, Vol. 59, No. 6, 1995, pp. 1091-1100. doi:10.1016/0016-7037(95)00026-V

[29] C. Arbizzani, M. Mastragostino and L. Meneghello, "Characterization by Impedance Spectroscopy of a Polymer- based Supercapacitor," Electrochimica Acta, Vol. 40, No. 13-14, 1995, pp. 2223-2228. doi:10.1016/0013-4686(95)00167-D

[30] W. G. Pell and B. E. Conway, "Voltammetry at a de Levie Brush Electrode as a Model for Electrochemical Supercapacitor Behavior," Journal of Electroanalytical Chemistry, Vol. 500, No. 1-2, 2001, pp. 121-133. doi:10.1016/S0022-0728(00)00423-X

[31] P. Kurzweil and H-J. Fischle, "A New Monitoring Method for Electrochemical Aggregates by Impedance Spectroscopy," Journal of Power Sources, Vol, 127, No. 1-2, 2004, pp. 331-340. doi:10.1016/j.jpowsour.2003.09.030

[32] Z. Stević, "Supercapacitors Based on Copper Sulfides," Ph.D. Thesis, Electrotechnical Faculty, Belgrade, 2004.

[33] Z. Stević, Z. Andjelković and D. Antić, “A New PC and LabVIEW Package Based System for Electrochemical Investigations," Sensors, Vol. 8, No. 3, 2008, pp. 1819. 1831. doi:10.3390/s8031819

[34] Z. Stević, M. Rajčić-Vujasinović and A. Dekanski, "Estimation of Parameters Obtained by Electrochemical Impedance Spectroscopy on Systems Containing High Capacities," Sensors, Vol. 9, No. 9, 2009, pp. 7365-7373. doi:10.3390/s90907365 